\title{
The Role of AMPK Activation for Cardioprotection in Doxorubicin-Induced Cardiotoxicity
}

\author{
Kerstin N. Timm ${ }^{1}$ (D) Damian J. Tyler ${ }^{1,2}$
}

Published online: 8 February 2020

(C) The Author(s) 2020

\begin{abstract}
Doxorubicin is a commonly used chemotherapeutic agent for the treatment of a range of cancers, but despite its success in improving cancer survival rates, doxorubicin is cardiotoxic and can lead to congestive heart failure. Therapeutic options for this patient group are limited to standard heart failure medications with the only drug specific for doxorubicin cardiotoxicity to reach FDA approval being dexrazoxane, an iron-chelating agent targeting oxidative stress. However, dexrazoxane has failed to live up to its expectations from preclinical studies while also bringing up concerns about its safety. Despite decades of research, the molecular mechanisms of doxorubicin cardiotoxicity are still poorly understood and oxidative stress is no longer considered to be the sole evil. Mitochondrial impairment, increased apoptosis, dysregulated autophagy and increased fibrosis have also been shown to be crucial players in doxorubicin cardiotoxicity. These cellular processes are all linked by one highly conserved intracellular kinase: adenosine monophosphate-activated protein kinase (AMPK). AMPK regulates mitochondrial biogenesis via PGC1 $\alpha$ signalling, increases oxidative mitochondrial metabolism, decreases apoptosis through inhibition of mTOR signalling, increases autophagy through ULK1 and decreases fibrosis through inhibition of TGF $\beta$ signalling. AMPK therefore sits at the control point of many mechanisms shown to be involved in doxorubicin cardiotoxicity and cardiac AMPK signalling itself has been shown to be impaired by doxorubicin. In this review, we introduce different agents known to activate AMPK (metformin, statins, resveratrol, thiazolidinediones, AICAR, specific AMPK activators) as well as exercise and dietary restriction, and we discuss the existing evidence for their potential role in cardioprotection from doxorubicin cardiotoxicity.
\end{abstract}

Keywords AMPK $\cdot$ Doxorubicin $\cdot$ Cardiotoxicity $\cdot$ AICAR $\cdot$ Metformin

\section{Introduction}

\section{Doxorubicin-Induced Cardiotoxicity}

UK cancer survival rates across all cancer types have doubled in adults and children over the last 40 years and now stand at $50 \%$ [1]. Some cancers such as breast cancer even show survival rates of $80 \%$ [2]. These improvements can, in part, be attributed to the impact of chemotherapeutics such as doxorubicin (DOX) [3], which is an anthracycline antibiotic first

Kerstin N. Timm

kerstin.timm@dpag.ox.ac.uk

1 Department of Physiology Anatomy and Genetics, University of Oxford, Oxford, UK

2 Oxford Centre for Clinical Magnetic Resonance Research, University of Oxford, Oxford, UK isolated from Streptomyces peucetius [4]. However, with increasing numbers of cancer survivors, long-term side effects of chemotherapeutics are becoming ever more apparent, and this is especially devastating for childhood cancer survivors [5]. Cardiotoxicity is one of the most severe side effects of chemotherapy and is defined as a reduction in left ventricular ejection fraction (LVEF) of greater than $10 \%$ to a value lower than $50 \%$ [6]. DOX in particular is severely cardiotoxic, causing congestive heart failure in $\sim 5 \%$ of patients [7], though the incidence of DOX cardiotoxicity is dose dependent and can range from 3 to $18 \%$ [8]. This nowadays limits the recommended maximum lifetime dose of DOX to $<450 \mathrm{mg} / \mathrm{m}^{2}$ to lessen the risk of cardiotoxic side effects [9]. DOX also shows sex-related difference in cardiotoxicity in both patients and in preclinical models [10], with female cancer patients before puberty and after menopause most susceptible to DOXinduced cardiotoxicity [11]. Details on incidence, risk factors, timing and outcomes in cancer patients treated with DOX are reviewed elsewhere [12]. 
The prognosis in patients with DOX-induced congestive heart failure is poor [13]. Therefore, patients on DOX chemotherapy are monitored regularly to assess cardiac LVEF and chemotherapy cessation is recommended when values drop below 40\% [14]. PEGylated liposomal formulations of DOX can reduce the incidence of cardiotoxicity, though they have been associated with other side effects such as skin toxicity [15]. Currently, there are no cardiotoxicity-specific treatments, neither prophylactic nor curative, and cardioprotective drugs trialled in patients to treat DOX cardiotoxicity are sparse and include standard heart failure medications such as renin angiotensin system blockers and beta blockers [12, 16]. Therefore, there is an unmet clinical need for more targeted cardioprotective therapy for cancer survivors with DOX cardiotoxicity, or, even more importantly, prophylactic treatment for cancer patients receiving DOX to minimise the incidence of cardiotoxic side effects leading to heart failure. In order to hit a specific target, detailed knowledge of the underlying molecular mechanisms of DOX cardiotoxicity is required.

\section{Molecular Mechanisms of DOX-Induced Cardiotoxicity}

DOX accumulates in the heart by binding to cardiolipin in the inner mitochondrial membrane [17]. DOX clearance from the myocardium lags far behind plasma clearance [18], which may explain why the heart is so susceptible to DOX. Different mechanisms have been proposed for the cardiotoxic effect of DOX [19] (Fig. 1). The most popular and widely researched mechanism of DOX cardiotoxicity is oxidative stress, which has been reviewed in detail elsewhere [20, 21]. In brief, reactive oxygen species are thought to be generated by different mechanisms, including Fenton reaction with molecular iron and redox cycling on the quinone moiety of DOX. However, it has already been suggested that oxidative stress may not be at the core of DOX-induced cardiotoxicity as ironchelating agents, such as dexrazoxane, that should reduce oxidative stress have been only partially efficacious in patients or have even proven unsuccessful [22]. In addition, dexrazoxane is associated with some safety concerns, at least in paediatric patients [23], making the hunt for other specific cardioprotective agents all the more important.

The anti-cancer action of DOX is thought to be mainly due to inhibition of topoisomerase II $\alpha$, which leads to DNA double strand breaks and initiation of apoptosis. Topoisomerase II $\alpha$ does not exist in cardiomyocytes; however, a role for topoisomerase II $\beta$ in DOX cardiotoxicity has recently been proposed, potentially leading to DNA damage and mitochondrial impairment [24]. Mitochondria make up around $50 \%$ of the cardiomyocyte volume and are vitally important for energy generation through the sequential processes of tricarboxylic acid (TCA) cycle, electron transport chain and oxidative phosphorylation. Long-chain fatty acids and glucose are the main respiratory fuels for ATP generation in the heart. As DOX binds to cardiolipin, this perturbs protein function in the inner mitochondrial membrane, and, therefore, energy generation. Mitochondrial dysfunction in DOX cardiotoxicity has been reviewed comprehensively elsewhere [25]. Further recent review articles cover the role of autophagy $[26,27]$ and mitophagy [28] in DOX cardiotoxicity. Moreover, fibrosis plays a vital part in structural remodelling in DOX cardiotoxicity, initiated through TGF $\beta$ signalling, and this has been comprehensively reviewed recently [29]. It is evident that DOX cardiotoxicity is not attributable to one single target, rather, a multitude of proteins and pathways is affected and modulated by DOX. Therefore, it is unlikely that one specific drug targeting any specific protein alone will show meaningful clinical benefit in DOX cardiotoxicity. However, some of the above-described mechanisms are linked by a cellular master regulator, the adenosine monophosphate-activated protein kinase (AMPK), which regulates mitochondrial biogenesis and function as well as autophagy and fibrosis [30]. AMPK therefore provides a link between at least some of the proposed molecular mechanisms of DOX cardiotoxicity outlined above. In this review, we will introduce AMPK and its possible role in DOX cardiotoxicity and we will describe how AMPK activation by different means has already shown cardioprotection in animal models and in patients receiving DOX-based chemotherapy.

\section{AMPK}

\section{Structure and Function of AMPK}

AMPK is conserved across the animal kingdom, exists as orthologues in yeast and plants, and consists of different isoforms with tissue-specific expression [31]. AMPK is a heterotrimeric protein complex with a catalytic $\alpha$ and regulatory $\beta$ and $\gamma$ domains (Fig. 2). All three subunits display 2 different isoforms in the heart [32]. The $\alpha 1$ subunit is mostly expressed in cardiac endothelial cells [33] and the $\alpha 2$ subunit in cardiomyocytes [34]. AMPK is activated upon phosphorylation of its $\alpha$ subunit at Thr172 by one of two upstream kinases: liver kinase B1 (LKB1) [35] and calcium/ calmodulin-dependent protein kinase kinase II (CAMKK2) [36]. Phosphorylation of the Thr172 residue on the catalytic $\alpha 1$ subunit is thought to be the predominant mechanism of AMPK activation; nonetheless, several other phosphorylation sites have been shown to exist on AMPK (Thr258, Ser485 on $\alpha 1$, Ser491 on $\alpha 2$ and Ser96, Ser101 and Ser108 on $\beta 1$ ) [37]. Phosphorylation of the $\alpha 1$ and $\alpha 2$ subunits leads to similar activity, though the downstream substrates differ [38]. This means that activation of AMPK by differential phosphorylation on distinct threonine and serine residues may modulate AMPK activity more subtly than a simple binary 'on-and-off', 


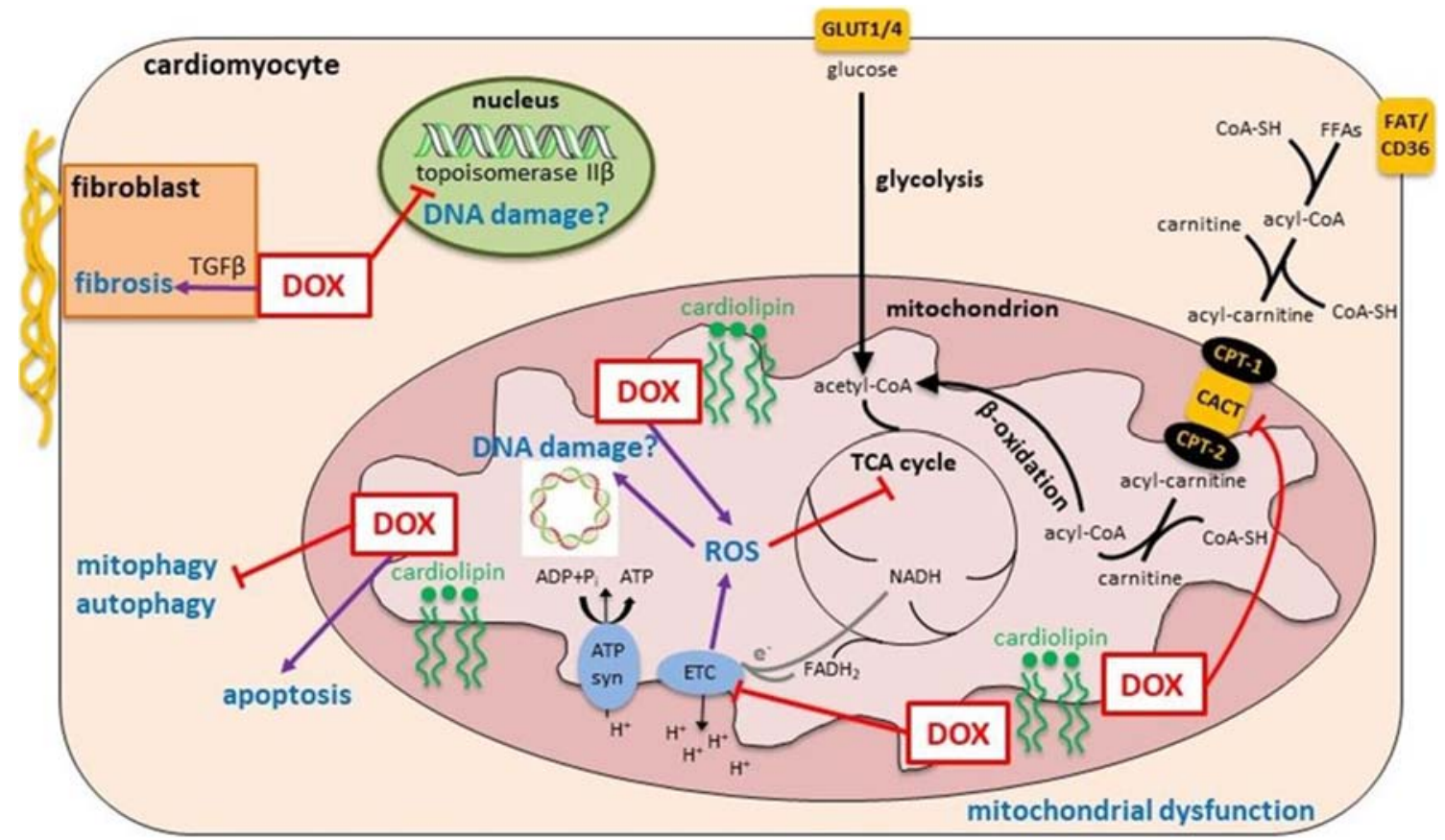

Fig. 1 Molecular mechanisms of doxorubicin-induced cardiotoxicity. Doxorubicin (DOX) preferentially binds to cardiolipin in the inner mitochondrial membrane. Through its proximity to mitochondrial membrane proteins, DOX interferes with the electron transport chain (ETC), which is thought to contribute to reactive oxygen species (ROS) generation and mitochondrial dysfunction. DOX also inhibits uptake of free fatty acids (FFAs) into mitochondria by inhibiting the carnitine acyl-carnitine translocase. ROS can furthermore be directly produced by DOX through redox cycling on the quinone moiety and by Fenton reaction with molecular iron. ROS inhibits several enzymes in the tricarboxylic acid (TCA) cycle and may damage mitochondrial DNA. DOX furthermore inhibits mitophagy and autophagy and induces apoptosis. In the nucleus, DOX inhibits topoisomerase II $\beta$, which may lead to DNA damage. In fibroblasts (inset), DOX triggers TGF $\beta$ signalling, which induces fibrosis. ATP syn, ATP synthase; CoA-SH, coenzyme A; CPT-1/2, carnitine palmitoyltransferase; FAT, fatty acid transporter; GLUT, glucose transporter

lipogenesis and increases hepatic $\beta$-oxidation and reduces adipocyte lipolysis and lipogenesis, which has made it an attractive drug target for the treatment of type 2 diabetes [50]. Despite its obvious regulation of lipid metabolism in the liver and adipose tissue, AMPK activation has been specifically associated with the beneficial effects of some anti-diabetic drugs on cardiovascular diseases [51]. In addition, AMPK activation has been proposed as a therapeutic target in heart failure [52], where its cardioprotective role is thought to be due to mechanisms beyond regulation of cellular energy metabolism [53]. Consequently, increased autophagy [54] and decreased fibrosis [55] are thought to play an important role in the cardioprotective potential of AMPK activation. Specifically, AMPK phosphorylates the mammalian Unc-51 like autophagy activating kinase (ULK1) at Ser317 and Ser777, promoting autophagy, whereas mTOR, which is inhibited by AMPK, phosphorylates UKL1 on Ser757 and inhibits autophagy by disrupting the AMPK/ULK1 pathway [56]. TGF $\beta$ signalling increases the expression of SMAD2/3 transcription factors, leading to dedifferentiation of cardiac fibroblasts into cardiomyoblasts, which in turn secrete extracellular matrix proteins leading to cardiac fibrosis [57] and AMPK negatively regulates TGF $\beta$ signalling to act antifibrotically [58]. 


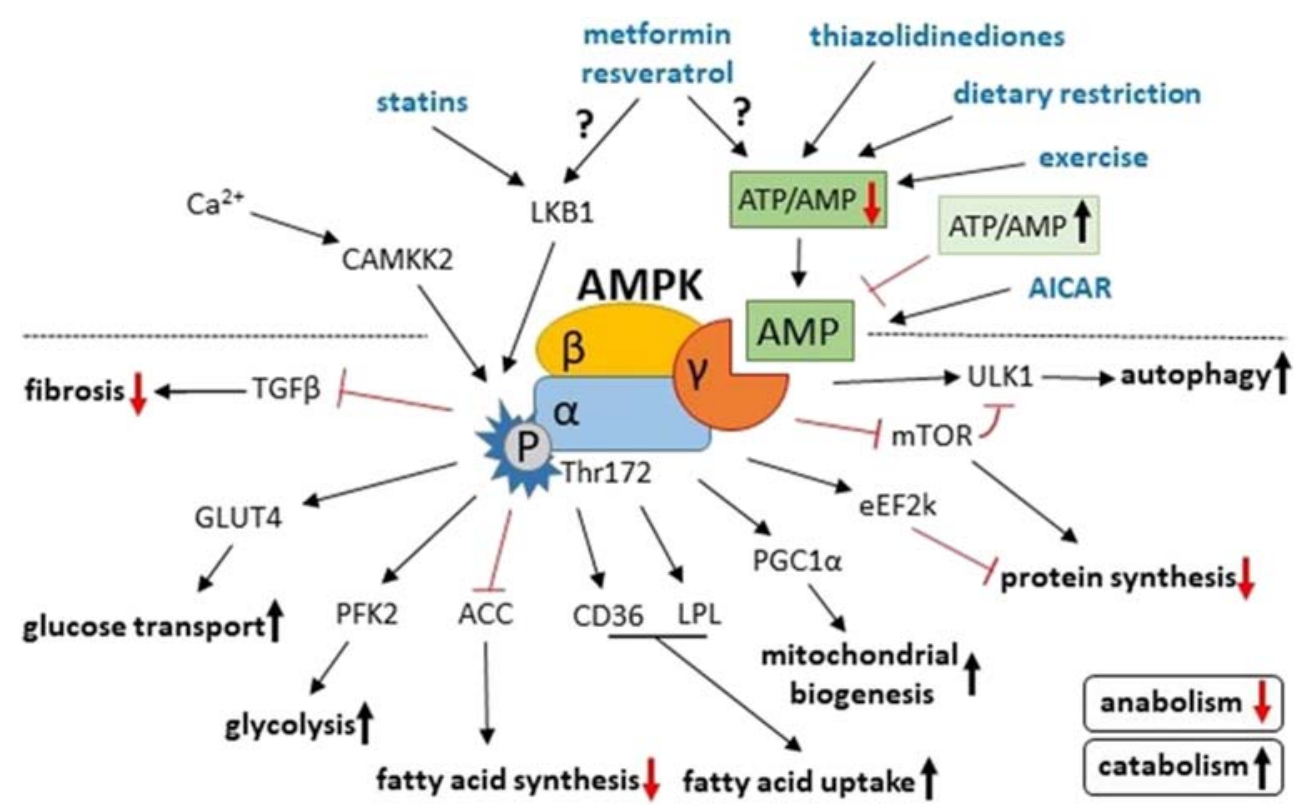

Fig. 2 AMPK activation and downstream effects in the heart. AMPK is activated by phosphorylation on its $\alpha$ subunit (Thr172) via calcium/ calmodulin-dependent protein kinase kinase II (CAMKK2) and liver kinase B1 (LKB1). AMP acts as an allosteric regulator on the $\gamma$ subunit, preventing dephosphorylation of AMPK. This occurs when the ATP to AMP ratio is low, signalling a low-energy state. A low ATP to AMP ratio is also present during exercise and dietary restriction and can be pharmacologically achieved with thiazolidinediones and potentially with metformin and resveratrol. 5-aminoimidazole-4-carboxamide riboside (AICAR) is an AMPK mimetic and thus does not rely on the ATP to AMP ratio for AMPK activation. LKB1 can be activated through sirtuin 1-mediated

\section{The Role of AMPK in DOX Cardiotoxicity}

The first evidence of the important role of AMPK inactivation in DOX cardiotoxicity comes from a study by Tokarska-Schlattner et al. in 2005 [59]. Short exposure (1 h) of isolated perfused rat hearts to low doses of DOX $(2 \mu \mathrm{M})$, representative of plasma levels in DOX-treated patients $(\sim 600 \mathrm{ng} / \mathrm{mL} 45 \mathrm{~min}$ after infusion of $60 \mathrm{mg} / \mathrm{m}^{2}$, equivalent to $\sim 1 \mu \mathrm{M}[60]$ ), led to reduced AMPK protein levels and AMPK phosphorylation as well as reduced phosphorylation of downstream targets such as acetylCoA carboxylase (ACC). This occurred before the onset of cardiac dysfunction and strongly suggests that perturbed cardiac energy homeostasis is involved in the development of DOX cardiotoxicity. In a separate study, DOX was also shown to inhibit AMPK protein expression and phosphorylation in the rat heart through DNA damage-induced Akt signalling, which activates mTOR signalling in a negative feedback loop and leads to cardiac remodelling [61]. While the aforementioned studies measured AMPK activation of the $\alpha$ subunit without isoform specificity, a different study in rats showed decreased mRNA expression of AMPK $\alpha 2$, the cardiomyocyte-specific isoform, upon chronic intravenous DOX treatment (weekly $3 \mathrm{mg} / \mathrm{kg}$ for 4 weeks) [62]. However, there is some discrepancy in the literature with respect to AMPK activation upon DOX treatment. For deacetylation by statins and potentially with metformin and resveratrol. Downstream targets of phosphorylated AMPK overall promote catabolic processes such as glucose uptake and glycolysis, fatty acid uptake, mitochondrial biogenesis and autophagy and inhibit anabolic processes such as protein synthesis (and fibrosis). ACC, acetyl-CoA carboxylase; CD36, fatty acid transporter; eEF2k, eukaryotic elongation factor 2 kinase; GLUT4, glucose transporter 4; LPL, lipoprotein lipase; mTOR, mammalian target of rapamycin; PFK2, phosphofructokinase 2; PGC1 $\alpha$, peroxisome proliferator-activated receptor-gamma coactivator $1 \alpha$; TGF $\beta$, transforming growth factor $\beta$; ULK1, Unc-51 like autophagy activating kinase

example, DOX was found to increase protein expression of AMPK $\alpha 2$ in mouse embryonic fibroblasts and mouse liver, leading to apoptosis via E2F1 signalling, whereas DOX decreased expression of AMPK $\alpha 1$ in the same models [63]. Furthermore, DOX was shown to induce AMPK activation (isoform unspecific) in rat H9c2 cardiomyoblasts [64]. Lastly, in a study of mice treated with a single high dose of intraperitoneal DOX (15 mg/kg), AMPK expression was increased and this was hypothesised to be due to decreased electron transport chain activity and reduced levels of ATP [65]. Since there are studies showing AMPK activation or inhibition of both the $\alpha 1$ and $\alpha 2$ isoforms of AMPK, isoform specificity cannot explain this discrepancy. However, one factor accounting for opposing findings across different studies may be the vast array of model systems (e.g. mice, rats, cardiomyocytes, mouse embryonic fibroblast) and treatment schemes (ip, iv, single dose, chronic weekly dose, low dose, high dose), which are employed to assess DOX cardiotoxicity, which may yield different results that do not necessarily reflect molecular events with clinically relevant doses and models. However, most studies agree with cardiac AMPK inhibition in response to DOX. The exact mechanism of AMPK inactivation by DOX remains elusive, though the stress-inducible sestrin proteins have been shown to play a role [66]. Sestrins are involved in oxidative stress defence and regulate AMPK 
signalling [67] and loss of sestrin function renders mice more susceptible to DOX cardiotoxicity [66].

\section{AMPK-Activating Agents and Their Role in DOX Cardioprotection}

\section{Overview of AMPK-Activating Agents}

AMPK-activating agents are highlighted in Fig. 1 and include the commonly prescribed anti-diabetic drug metformin and cholesterol-lowering statins, which can activate AMPK via phosphorylation of Thr172 in the $\alpha 1$ subunit $[68,69]$. AMPK phosphorylation by metformin and statins may be independent of the cellular ATP to AMP ratio [70], though the exact mechanism is unclear. Resveratrol, a polyphenolic anti-oxidant, has been shown to activate AMPK by both changing the cellular energy state and by activating its upstream kinase, LKB1, through deacetylation by sirtuin 1 [71]. The tissue ATP to AMP ratio can also be reduced by the PPAR $\gamma$ agonists, namely the antidiabetic thiazolidinediones, which activates AMPK allosterically through increased levels of AMP [72]. Small molecule AMPmimetics, for example by 5-aminoimidazole-4-carboxamide riboside (AICAR), can activate AMPK allosterically [73]. AMPK can furthermore be activated by a range of specific synthetic AMPK activators [74]. Lastly, the ATP to AMP ratio can be decreased by exercise [75] and caloric restriction [76], indicating an energy-deficient state which activates AMPK. All the above agents/methods have been shown to increase levels of AMPK and/or AMPK phosphorylation, and have been used in models of DOX cardiotoxicity, demonstrating cardioprotective effects. However, these cardioprotective effects, while mediated via mechanisms known to involve AMPK (such as autophagy), have not always been shown experimentally to act directly via AMPK. In the following sections, we will introduce each of these agents separately and outline studies that have trialled them in the context of DOX cardiotoxicity, whether they conclusively showed involvement of AMPK signalling (summarised in Table 1) or not. We hope that this summary of evidence will shed some light on the potential role that AMPK-activating agents may play in cardioprotection for DOX cardiotoxicity.

\section{Metformin}

Metformin is a first-line drug for type 2 diabetic patients and the main mechanism of metformin's anti-diabetic action is believed to be inhibition of complex I in the electron transport chain, which in turn inhibits hepatic gluconeogenesis [68]. This is linked to a risk of lactic acidosis [95] and therefore, metformin administration can be dangerous in some patients and is usually not recommended for diabetic patients with heart failure [96]. A more recent opinion, however, considers the risk of metformin in diabetic patients with heart failure as minimal and suggests that the cardioprotective benefit outweighs this risk [97]. Indeed, the metabolic and anti-fibrotic effects of metformin on the failing heart have been reviewed, encouraging large-scale clinical trials in diabetic patients with heart failure [98]. Moreover, metformin improves cardiac LVEF and survival in mice with ischaemiainduced heart failure [99]. Part of metformin's anti-diabetic action is thought to be due to AMPK activation, which may be independent of changes in the ATP to AMP ratio due to complex I inhibition [70]. Metformin furthermore has dose-dependent effects [100] and its mechanism of action can be AMPK dependent or AMPK independent [101]. Metformin has been show to activate AMPK in adipose tissue [102], skeletal muscle [103] and hepatocytes, which decreases the activity of acetyl-CoA carboxylase, thereby reducing fatty acid synthesis and improving fatty acid oxidation [104]. In the heart, metformin promotes autophagy by both cytoplasmic AMPK $\alpha 1$ and nuclear AMPK $\alpha 2$ pathways [105], while it attenuates cardiac fibrosis through the TGF $3-S M A D 3$ pathway independent of AMPK [106].

In relation to DOX cardiotoxicity, low-dose metformin showed protective effects on rat $\mathrm{H} 9 \mathrm{c} 2$ cardiomyoblasts treated with DOX, and this was due to AMPK activation and increased expression of the platelet-derived growth factor receptor (PDGFR), which increased cell viability [77]. In another study using rat $\mathrm{H} 9 \mathrm{c} 2$ cardiomyoblasts, metformin was able to counteract hydrogen peroxide-induced mitochondrial DNA damage, and this was due to the prevention of PPAR $\alpha$ cyclophilin D interaction due to AMPK activation [78]. Metformin was also shown to normalise markers of autophagy (LC3B-II and p62) in rats treated with DOX, which resulted in improved cardiac function [107]. However, while cardiac levels of phosphorylated AMPK appeared to be increased in this model, this was not statistically significant. Metformin has also been shown to activate cardiac AMPK downstream of adiponectin signalling from the adipose tissue, which conferred protection from DOX in mouse HL-1 cardiomyocytes [79] and in mouse hearts in vivo [80]. This may explain how AMPK activation can be achieved in the heart despite unaltered cardiac energy status (ATP to AMP ratio). However, doses of metformin that showed AMPK activation in preclinical studies are usually 2-3 orders of magnitude higher than clinical doses [108], which potentially precludes optimum AMPK-mediated cardioprotection in man. One phase II trial using metformin in breast cancer patients receiving DOX has previously been started but was terminated due to insufficient accrual of patients. ${ }^{1}$ Future clinical trials are warranted to assess the potential cardioprotective effect of metformin in DOX-treated cancer patients, though careful consideration of dose and treatment scheme have to be made to ensure maximal cardioprotective potential through AMPK activation without severe adverse effects.

\footnotetext{
${ }^{1}$ https://clinicaltrials.gov/ct2/show/NCT02472353?term=metformin\&cond= Cardiotoxicity\&rank $=1$
} 
Table 1 Preclinical studies showing AMPK-mediated cardioprotective effects of different compounds in models of DOX cardiotoxicity

\begin{tabular}{|c|c|c|c|c|}
\hline Compound & $\begin{array}{l}\text { Mechanism of AMPK } \\
\text { activation }\end{array}$ & $\begin{array}{l}\text { Downstream effect mediating } \\
\text { cardioprotection }\end{array}$ & Model system & Reference \\
\hline \multirow[t]{4}{*}{ Metformin } & \multirow{2}{*}{$\begin{array}{l}\text { Decreased ATP to AMP ratio? ATP } \\
\text { to AMP ratio-independent } \\
\text { AMPK } \alpha 1 \text { phosphorylation? }\end{array}$} & $\begin{array}{l}\text { Increased PDGFR expression and increased } \\
\text { cell viability }\end{array}$ & Rat H9c2 cardiomyoblasts & [77] \\
\hline & & $\begin{array}{l}\text { Decreased oxidative stress, prevention of } \\
\text { PPAR } \alpha \text {-cyclophilin D interaction }\end{array}$ & Rat H9c2 cardiomyoblasts & [78] \\
\hline & \multirow[t]{2}{*}{ Via adiponectin receptor? } & Decreases apoptosis & HL-1 mouse cardiomyocytes & [79] \\
\hline & & Decreased apoptosis and fibrosis & C57BL/6 and APN-SE mice & [80] \\
\hline \multirow[t]{5}{*}{ Resveratrol } & \multirow{2}{*}{$\begin{array}{l}\text { Decreased ATP to AMP ratio? ATP } \\
\text { to AMP ratio-independent } \\
\text { AMPK } \alpha 1 \text { phosphorylation? }\end{array}$} & Decreased apoptosis and fibrosis & Wistar rats & [81] \\
\hline & & Decreased fibrosis via reduced TGF $\beta$ & F344 rats & [82] \\
\hline & $\begin{array}{l}\text { Sirtuin } 1 \text { activation and } \\
\text { deacetylation of LKB1 leading to } \\
\text { AMPK } \alpha 1 \text { phosphorylation }\end{array}$ & Decreased apoptosis & Rat H9c2 cardiomyoblasts & [83] \\
\hline & Decreased ATP to AMP ratio? ATP & Decreased apoptosis & Rat H9c2 cardiomyoblasts & [84] \\
\hline & $\begin{array}{l}\text { to AMP ratio-independent } \\
\text { AMPK } \alpha 1 \text { phosphorylation? }\end{array}$ & $\begin{array}{l}\text { Decreased apoptosis and increased autophagy } \\
\text { via ULK } 1 / \mathrm{mTOR}\end{array}$ & Rat $\mathrm{H} 9 \mathrm{c} 2$ cardiomyoblasts & [85] \\
\hline Quercetin & Increased expression of AMPK $\alpha 2$ & Increased expression of PPAR $\alpha$ and PCG- $1 \alpha$ & Sprague-Dawley rats & [86] \\
\hline AICAR & $\begin{array}{l}\text { AMP-mimetic (allosteric AMPK } \\
\text { activation) }\end{array}$ & Decreased p53-mediated apoptosis & Mouse embryonic fibroblasts & [87] \\
\hline 2-Deoxyglucose & Decreased ATP to AMP ratio & Decreased apoptosis and increased autophagy & Rat neonatal cardiomyocytes & [88] \\
\hline FGF21 & $\begin{array}{l}\text { Via sirtuin } 1 \text { activation and } \\
\text { deacetylation of LKB } 1 \text { leading to } \\
\text { AMPK } \alpha 1 \text { phosphorylation }\end{array}$ & $\begin{array}{l}\text { Decreased apoptosis, inflammation and } \\
\text { oxidative stress }\end{array}$ & $\begin{array}{l}\text { Rat H9c2 cardiomyoblasts, adult } \\
\text { mouse cardiomyocytes and } \\
\text { 129S1/SyImJ mice }\end{array}$ & [89] \\
\hline Liraglutide & $?(\mathrm{GLP}-1$ agonist $)$ & $\begin{array}{l}\text { Reduced inflammation and necrosis via Akt } \\
\text { signalling }\end{array}$ & Wistar rats & {$[90]$} \\
\hline Exenatide & ? (GLP-1 agonist) & Increased autophagy & Rat $\mathrm{H} 9 \mathrm{c} 2$ cardiomyoblasts & [91] \\
\hline Melatonin & ? & $\begin{array}{l}\text { Reduced mitochondrial oxidative stress and } \\
\text { apoptosis, increased PGC1 } \alpha \text { expression }\end{array}$ & $\begin{array}{l}\text { Rat } \mathrm{H} 9 \mathrm{c} 2 \text { cardiomyoblasts and } \\
\text { C57BL/6 mice }\end{array}$ & [92] \\
\hline Oleuropein & $?$ & $\begin{array}{l}\text { Reduced apoptosis, oxidative stress and } \\
\text { normalised protein synthesis }\end{array}$ & Wistar rats & [93] \\
\hline Aspalathin & ? & Decreased apoptosis and increased autophagy & Rat $\mathrm{H} 9 \mathrm{c} 2$ cardiomyoblasts & [94] \\
\hline
\end{tabular}

\section{Statins}

Statins are commonly prescribed lipid-lowering agents and they have been shown to activate AMPK in mouse myocardium by increased phosphorylation of Thr172 of the $\alpha 1$ subunit [69]. This activation of AMPK is dependent on reactive nitrogen species [109] and/or Rac1 [110], at least in endothelial cells. Rac1 inhibition was shown in a mouse model of DOX cardiotoxicity treated with pitavastatin, leading to attenuated myocyte apoptosis and improved contractile function [111]. In a study with lovastatin in DOX-treated mice, inhibition of Rac1 signalling could furthermore achieve a reduction in cardiac fibrosis [112]. Moreover, lovastatin showed beneficial effects in a mouse model of chronic DOX cardiotoxicity [113]. However, while markers of cardiac damage (e.g. BNP) could be reduced with lovastatin in this setting, ejection fraction could not be rescued. In a rat model of DOX cardiotoxicity, rosuvastatin co-administration showed beneficial effects on cardiac LV function and myocardial injury 4 weeks after treatment cessation [114]. Rosuvastatin moreover reduced DOX-induced pro-inflammatory effects in rats [115]. Atorvastatin in turn ameliorated oxidative stress and DNA and cellular damage in a mouse model of DOX cardiotoxicity [116]. Lastly, fluvastatin pretreatment in an acute model of DOX cardiotoxicity exerted protective effects on cardiac oxidative stress, inflammation and apoptosis [117]. None of the above-mentioned studies, however, looked at the mechanism of statin cardioprotection with respect to AMPK activation directly. AMPK involvement in at least some of these studies is, however, likely given the fact that (a) statins do activate AMPK [69] and (b) some of the downstream effects such as fibrosis are linked to AMPK signalling [55].

From a clinical perspective, it has been shown in a retrospective study of female breast cancer patients treated with anthracycline-based chemotherapy that uninterrupted statin use throughout the follow-up period ( $2.55 \pm 1.68$ years) was associated with a significantly lower hazard ratio $(0.3)$ for new-onset heart failure hospitalisation [118]. The use of statins as a cardioprotective prophylactic treatment in cancer patients on anthracycline-based chemotherapy may therefore be beneficial and further clinical trials are warranted.

\section{Resveratrol}

The polyphenolic stilbene 3,5,40-trihydroxy-trans-stilbene (resveratrol) is produced by a multitude of plants and is a constituent of red wine [119]. Concentrations of resveratrol used in research are far greater than doses achievable by diet alone [120], which makes nutritional health claims of foods containing resveratrol in the cardioprotective setting 
questionable. However, resveratrol has been implicated as a cardioprotective drug for many cardiovascular diseases both in preclinical studies [121] and in man [122], and this is thought to be largely due to its anti-inflammatory and anti-oxidant action [123]. Of specific interest for the topic of this review, resveratrol has been shown to lead to activation of AMPK and to reduce cardiac fibrosis and hypertrophy in a mouse model of pressure overload by transverse aortic constriction [124]. Moreover, resveratrol has shown cardioprotective effects in animal models of DOX-induced cardiotoxicity by mitigating oxidative stress and apoptosis, modulating cardiomyocyte autophagy and ameliorating fibrosis, and studies supporting this have been reviewed recently [125].

Specifically, resveratrol has been shown to decrease fibrosis in DOX-treated rats [81]. In cells, this was due to upregulation of sirtuin 1 , with concomitant decrease in TGF $\beta$ signalling in cardiac fibroblasts [82] and in H9c2 cardiomyoblasts [83]. Sirtuin 1 is upstream of the AMPK-phosphorylating kinase LKB1, initiating its activation by deacetylation [126], which explains its cardioprotection action in DOX cardiotoxicity [127]. Resveratrol also protects rat $\mathrm{H} 9 \mathrm{c} 2$ cardiomyoblasts from doxorubicin-induced apoptosis by increasing AMPK phosphorylation and decreasing p53 expression [84]. In the same model system, resveratrol reduced apoptosis and increased autophagy downstream of AMPK activation, leading to ULK1 phosphorylation and decreasing phosphorylation of mTOR [85]. Another study, however, reported an inhibitory effect of resveratrol on autophagy, leading to protection against DOX cytotoxicity in neonatal rat ventricular cardiomyocytes, and this was independent of both AMPK and mTOR signalling and attributed to inhibition of p70S6 kinase [128]. Resveratrol furthermore was shown to elicit an anti-apoptotic and pro-autophagic effect by inhibiting the $\mathrm{E} 2 \mathrm{~F} 1 / \mathrm{AMPK} \alpha 2$ and E2F1/mTOR pathways [129], which is counterintuitive, though AMPK $\alpha 2$ has been shown previously to account for the cytotoxic effects of DOX [63]. Another non-resveratrol polyphenolic compound, quercetin, also conferred cardioprotection in rats, and this was associated with increased expression of AMPK $\alpha 2$, PPAR $\alpha$ and PCG- $1 \alpha$ [86]. No clinical trials have been performed to date using resveratrol in cancer patients on DOX-based chemotherapy, though data from preclinical studies above suggest that resveratrol may have cardioprotective effects in DOX-treated cancer patients.

\section{Thiazolidinediones}

Thiazolidinediones are a class of anti-diabetic drugs which are ligands of the peroxisome proliferator-activated receptor- $\gamma$ (PPAR $\gamma$ ) [130]. Thiazolidinediones have also been shown to activate AMPK by different mechanisms [72, 131-133]. The thiazolidinedione troglitazone can increase mitochondrial biogenesis in cancer cells [134]. Deus et al. assessed whether troglitazone could decrease DOX toxicity in rat $\mathrm{H} 9 \mathrm{c} 2$ cardiomyoblasts by increasing mitochondrial number by the same mechanism; however, with the incubation times and concentrations employed in this study, no increase in mitochondrial content could be achieved and no protective effects were observed [135]. A meta-analysis of clinical trials in type 2 diabetic patients on either rosiglitazone or pioglitazone therapy revealed an increased risk of developing congestive heart failure due to fluid overload [136] making their clinical use to prevent heart failure in cancer patients receiving DOX-based chemotherapy unlikely.

\section{AICAR}

The AMP-mimetic 5-aminoimidazole-4-carboxamide riboside (AICAR) is the prototype adenosine-regulating agent for reducing myocardial ischemic injury [137] and was shown almost 40 years ago to improve purine nucleotide synthesis in both cardiac and skeletal muscles [138]. AICAR furthermore activates AMPK [73] due to its structural equivalence to AMP [139], which increases mitochondrial biogenesis [140] and oxidative metabolism [141]. AICAR also increases autophagy downstream of AMPK by inhibiting mTOR signalling, thereby preventing apoptosis and improving cardiac function in a model of endotoxin-induced myocardial inflammation [142]. AICAR administration also leads to a reduction in cardiac fibrosis as it inhibits TGF $\beta$ signalling, thereby preventing adverse cardiac remodelling due to pressure overload [143]. AICAR furthermore reduces lipid synthesis and increases fatty acid oxidation in the liver in an AMPK-dependent manner [144], which could lead to reduced lipotoxicity of the heart. Publications employing AICAR in the DOX cardiotoxicity setting are, however, sparse. One study used AICAR in DOX-treated mouse embryonic fibroblasts and H9c2 rat cardiomyoblasts, which reversed SIRT1 dysfunction and p53 accumulation, leading to reduced cell death [87]. However, no studies have been published to date using AICAR in animal models of DOX cardiotoxicity in vivo. AICAR has a short half-life and has to be administered intravenously, which along with some side effects such as hypoglycaemia and bradycardia makes its clinical use challenging [145], though new synthetic AICAR derivatives with increased stability and AMPK activation potential are being synthesised [146]. Furthermore, AICAR has AMPK-independent effects, which means that off-target effects are likely, making specific AMPK activators potentially more attractive for clinical use [147].

\section{Exercise}

Several preclinical studies have employed exercise as a cardioprotective strategy in DOX cardiotoxicity, and those studies are summarised in a recent review [148]. However, the cardioprotective mechanisms of exercise discussed in 
reference [148] are not directly attributed to AMPK activation. For example, cardioprotection in a mouse model of DOX cardiotoxicity with endurance treadmill exercise was correlated with increased autophagy and the authors conclude that this was despite no changes to AMPK/ULK1/mTOR signalling [149]. However, autophagy has been shown previously to be regulated by AMPK/ULK1/mTOR signalling [56]. Furthermore, the data in reference [149] does show a normalisation of ULK1 protein levels and mTOR phosphorylation with exercise, as well as an increase in phosphorylated AMPK, albeit the latter was not statistically significant. No other preclinical studies have directly assessed AMPK activation status in the heart to correlate with the cardioprotective findings of exercise. Clinical studies assessing the potential cardioprotective effects of exercise in heart failure in general as well as the cellular and molecular basis of such cardioprotective effects are summarised in reference [150]. In relation to DOX cardiotoxicity, an exercise bout performed $24 \mathrm{~h}$ prior to doxorubicin treatment reduced circulating NTproBNP and increased systolic function in female breast cancer patients indicative of reduced acute DOX cardiotoxicity [151]. However, in the same patient group, exercise did not have an effect on markers of subclinical cardiotoxicity 7 14 days after DOX, even though there was a positive systemic effect on haemodynamics, musculoskeletal symptoms, mood and body weight [152]. The intensity and timing of exercise with respect to DOX treatment may alter what cardioprotective effect can be achieved and it may be beneficial to assess different exercise protocols in cancer patients on DOX chemotherapy.

\section{Dietary Restriction}

The ATP to AMP ratio is indicative of the cellular energy state and can be modulated by dietary restriction [153]. Moderate diet restriction has also been shown to increase AMPK expression, fatty acid oxidation rates, ATP levels and cardiac function in rats treated with a single high dose of intraperitoneal DOX compared with rats on an ad libitum diet [154]. AMPK activation, reduced apoptosis and increased autophagy could furthermore be achieved in DOX-treated rat neonatal cardiomyocytes with the caloric restriction mimetic 2deoxyglucose [88]. In addition, voluntary exercise (wheel running) in combination with caloric restriction reduced cardiotoxicity in DOX-treated rats, though AMPK expression and phosphorylation status or downstream effectors were not assessed in this study [155]. Contrary to the above, DOX has also been shown to supress the ULK1 pathway through inhibition of AMPK, leading to diminished autophagy, which could be reversed by prior starvation [156]. Given that cancer patients already suffer from their primary disease and the side effects of chemotherapy, it is questionable whether caloric restriction would be a sensible cardioprotective strategy for these patients.

\section{Specific AMPK Agonists}

All AMPK-activating agents/strategies above also have offtarget effects, and the exclusive role of AMPK activation for cardioprotection in DOX cardiotoxicity is challenging to ascribe. However, specific AMPK agonists have also been developed, which are targeted to AMPK directly and therefore show less off-target effects. One of these agents is the panAMPK activator, MK-8722 [157], which activates all 12 mammalian AMPK complexes. MK-8722 was shown to activate AMPK in rodent and rhesus monkey skeletal muscle, which led to insulin-independent glucose update in the skeletal muscle but was associated with cardiac hypertrophy [158]. The adenosine derivative and AMPK activator IMM-H007 furthermore showed decreased cardiac fibrosis and increased cardiac ejection fraction in a mouse model of angiotensin IIinduced cardiac remodelling [159]. Another AMPKactivating agent is compound A-769662 [160], which activates AMPK both allosterically and by inhibiting dephosphorylation at the $\alpha$ subunit [161]. This compound shows AMPK activation of partially purified rat liver AMPK, inhibits fatty acid synthesis in rat hepatocytes and decreases liver malonylCoA levels in rats in vivo, indicating inhibition of ACC downstream of AMPK. A-769662 furthermore showed protection against ischaemia-reperfusion injury in a study in mice [162]. Interestingly, A-769662 on its own cannot increase glucose uptake in the heart, but shows synergistic effects with other AMPK activators, such as metformin, which potentiates the AMPK-activating effect and leads to protection from ischaemia-induced ROS formation and cell death [163]. A769662 has not been tested in models of DOX cardiotoxicity, though its interaction with epirubicin on breast cancer cells has been assessed in comparison with metformin [164]. However, compound A-769662 has poor bioavailability and thus may not be useful in clinical settings, requiring long-term daily administration. Further $\beta 1$-selective, $\gamma$-selective or panAMPK activators have been developed and tested in cancer models and the kidney but not the heart [74] or are in development and have not yet been tested in vivo [165]. It would be interesting to test some of these specific AMPK activators in models of DOX cardiotoxicity to more directly establish the role of AMPK activation in cardioprotection without any offtarget effects.

\section{AMPK Activation by Other Compounds}

A substantial list of compounds not classically associated with AMPK activation have been shown to have AMPK-mediated cardioprotective effects on DOX cardiotoxicity. For example, fibroblast growth factor 21 (FGF21), a regulator of glucose 
and lipid metabolism, could elicit cardioprotective effects in DOX-treated mice [89]. FGF21 led to AMPK activation by a cascade involving sirtuin 1 activation and deacetylation of LKB1, rendering it active to phosphorylate AMPK, which in turn was able to reduce inflammatory factors, oxidative stress and apoptosis. A promising new class of anti-diabetic drugs, the sodium-glucose cotransporter-2 (SGLT2) inhibitors, have shown improved cardiovascular outcomes in type 2 diabetic patients [166]. Empagliflozin is an SGLT2 inhibitor which dramatically reduced hospitalisation due to heart failure in diabetic patients [167]. Different SGLT2 inhibitors have moreover been shown to activate AMPK in cardiofibroblasts [168] and adipocytes [169]. Two recent studies furthermore showed that SGLT2 inhibitors preserve heart function in mice [170] and rats [171] treated with DOX. Another antidiabetic drug, liraglutide, a glucagon-like peptide-1 (GLP1) analogue, protected rats from DOX-induced inflammation and necrosis by activating AMPK and the Akt signalling pathway [90]. Increased autophagy and reduced apoptosis could also be achieved with another GLP1 analogue, exanitide, in a rat model of DOX cardiotoxicity, where AMPK-mediated increase in autophagy improved cardiac LVEF [91]. The peptide hormone ghrelin showed cardioprotection by inhibiting autophagy through AMPK inhibition [172], which is counter to most studies attributing AMPK activation rather than inhibition to confer cardioprotection. In this study, AMPK phosphorylation was increased by DOX, though the treatment scheme both in their cell and in vivo models was far more severe than usually employed methods (10 $\mu \mathrm{M}$ DOX in cells and 4 weekly intraperitoneal injections of $8 \mathrm{mg} / \mathrm{kg}$ DOX in mice), which may explain the counterintuitive findings. Recently, the endogenous sleep-regulating hormone melatonin, which also has anti-oxidant capacity, was shown to reduce DOX cardiotoxicity in both rat $\mathrm{H} 9 \mathrm{c} 2$ cardiomyoblasts and in C57BL/6 mice, via upregulation of AMPK/PGCla signalling [92]. Oleuropein, which is a natural phenolic compound, reduced DOX-induced cardiotoxicity in Wistar rats and this was attributed to AMPK activation and a reversal of oxidative stress, apoptosis and impaired protein synthesis [93]. The rooibos flavonoid aspalathin also protects rat H9c2 cardiomyoblasts from DOX-toxicity by reducing apoptosis in an AMPK- and p53-dependent manner [94]. Other compounds based on traditional Chinese medicines such as Astragalus membranaceus [173], fermented Cordyceps sinensis [174], isodunnianol [175] and DT-010 [176] also showed AMPK-mediated cardioprotective effects in cell and mouse models of DOX cardiotoxicity. Other agents including salicylate [177], the endogenous and systemic anti-coagulant activated protein $\mathrm{C}$ [178] and the macrophage migration inhibitory factor [179], are also known to activate AMPK but have not been trialled in DOX cardiotoxicity.

\section{Conclusion}

More than 50,000 women are diagnosed with breast cancer in the UK every year and $\sim 30 \%$ of breast cancer patients are treated with anthracycline-based chemotherapy [180]. Breast cancer 10-year survival rates in the UK are now at $80 \%$ [2], and female breast cancer survivors are the most common patient group to suffer from DOX-HF. DOX cardiotoxicity is likely mediated by a combination of mechanisms, and some of these are linked by the cellular master regulator, AMPK. Cardioprotection through AMPK activation could, indeed, be achieved in preclinical studies with some AMPK-activating agents, such as metformin, statins and resveratrol as outlined in this review. None of these treatments though has reached clinical practise or even clinical trials until now, bar one phase II trial in breast cancer patients on DOX-based chemotherapy with metformin, though this trial was terminated due to insufficient patient accrual. ${ }^{2}$ The multitude of animal and cell models and varying concentrations and timescales of DOX used to study both the mechanism of DOX cardiotoxicity and the effect of AMPK-activating agents in this setting make it difficult to find consensus on molecular mechanisms. Furthermore, most of the AMPK-activating agents have offtarget effects and are not AMPK specific. It may be useful to employ specific AMPK activators in comparison with commonly used agents with AMPK-activating capacity, such as metformin, statins and resveratrol, in models of DOX cardiotoxicity in order to definitively ascribe their cardioprotective roles to AMPK activation and to push them closer to clinical use. In addition to their cardioprotective function, statins have shown anti-tumour activity in three different mouse tumour models [181]. This may be, at least in part, due to AMPK activation, as different strategies to activate AMPK have been shown to provide anti-cancer activity in a range of cancer models $[182,183]$. Strikingly, the AMPKactivating agents, metformin and AICAR have been shown to both attenuated cardiotoxicity and to reduce chemotherapy resistance [184] and proliferation [185] in human breast cancer cells and both AICAR and metformin can be safely administered alongside chemotherapy in patients [186, 187]. This makes their use as cardioprotective agents in cancer patients on DOX-based chemotherapy all the more attractive and feasible in the future.

Funding Information The authors would like to acknowledge funding from the British Heart Foundation (FS/16/7/31843 for KNT and FS/19/ $18 / 34252$ for DJT).

Compliance with Ethical Standards This article does not contain any studies with human participants or animals performed by any of the authors.

\footnotetext{
${ }^{2}$ https://clinicaltrials.gov/ct2/show/NCT02472353?term=metformin\&cond= Cardiotoxicity\&rank=1.
} 
Conflict of Interest The authors declare that they have no conflict of interest.

Open Access This article is licensed under a Creative Commons Attribution 4.0 International License, which permits use, sharing, adaptation, distribution and reproduction in any medium or format, as long as you give appropriate credit to the original author(s) and the source, provide a link to the Creative Commons licence, and indicate if changes were made. The images or other third party material in this article are included in the article's Creative Commons licence, unless indicated otherwise in a credit line to the material. If material is not included in the article's Creative Commons licence and your intended use is not permitted by statutory regulation or exceeds the permitted use, you will need to obtain permission directly from the copyright holder. To view a copy of this licence, visit http://creativecommons.org/licenses/by/4.0/.

\section{References}

1. Beral V, Peto R. UK cancer survival statistics [Internet]. BMJ. 2010 [cited 2019 Nov 11]. p. 309. Available from: https://www. cancerresearchuk.org/health-professional/cancer-statistics-forthe-uk

2. Cancer Research UK. Breast cancer survival statistics [Internet]. 2005-2009. 2014 [cited 2019 Nov 11]. p. 1-5. Available from: http://www.cancerresearchuk.org/cancer-info/cancerstats/types/ breast/survival/breast-cancer-survival-statistics

3. A'Hern RP, Smith IE, Ebbs SR. Chemotherapy and survival in advanced breast cancer: The inclusion of doxorubicin in Cooper type regimens. Br J Cancer. 1993;67:801-5.

4. Rimal H, Lee SW, Lee JH, Oh TJ. Understanding of real alternative redox partner of Streptomyces peucetius DoxA: Prediction and validation using in silico and in vitro analyses. Arch Biochem Biophys. 2015;585:64-74.

5. Ryan TD, Nagarajan R, Godown J. Cardiovascular Toxicities in Pediatric Cancer Survivors. Cardiol Clin. 2019;37:533-44.

6. Cardinale D, Colombo A, Bacchiani G, Tedeschi I, Meroni CA, Veglia F, et al. Early detection of anthracycline cardiotoxicity and improvement with heart failure therapy. Circulation. 2015;131: 1981-8.

7. Yu AF, Jones LW. Breast cancer treatment-associated cardiovascular toxicity and effects of exercise counter measures. CardioOncology. 2016;2:1.

8. von Hoff DD, Layard MW, Basa P, Davis HL, Von Hoff AL, Rozencweig M, et al. Risk factors for doxorubicin-induced congestive heart failure. Ann Intern Med. 1979;91:710-7.

9. Swain SM, Whaley FS, Ewer MS. Congestive heart failure in patients treated with doxorubicin: A retrospective analysis of three trials. Cancer. 2003;97:2869-79.

10. Meiners B, Shenoy C, Zordoky BN. Clinical and preclinical evidence of sex-related differences in anthracycline-induced cardiotoxicity. Biol Sex Differ. BioMed Central Ltd. 2018;9:38.

11. Cadeddu Dessalvi C, Pepe A, Penna C, Gimelli A, Madonna R, Mele D, et al. Sex differences in anthracycline-induced cardiotoxicity: the benefits of estrogens. Heart Fail Rev. 2019;24:915-25.

12. McGowan JV, Chung R, Maulik A, Piotrowska I, Walker JM, Yellon DM. Anthracycline Chemotherapy and Cardiotoxicity. Cardiovasc Drugs Ther. 2017;31:63-75.

13. Felker GM, Thompson RE, Hare JM, Hruban RH, Clemetson DE, Howard DL, et al. Underlying causes and long-term survival in patients with initially unexplained cardiomyopathy. N Engl J Med. 2000;342:1077-84.
14. Finet JE. Management of Heart Failure in Cancer Patients and Cancer Survivors. Heart Fail Clin. 2017;13:253-88.

15. Ansari L, Shiehzadeh F, Taherzadeh Z, Nikoofal-Sahlabadi S, Momtazi-Borojeni AA, Sahebkar A, et al. The most prevalent side effects of pegylated liposomal doxorubicin monotherapy in women with metastatic breast cancer: A systematic review of clinical trials. Cancer Gene Ther. 2017;24:189-93.

16. Padegimas A, Clasen S, Ky B. Cardioprotective strategies to prevent breast cancer therapy-induced cardiotoxicity. Trends Cardiovasc Med. 2020;30:22-8.

17. Goormaghtigh E, Chatelain P, Caspers J, Ruysschaert JM. Evidence of a complex between adriamycin derivatives and cardiolipin: Possible role in cardiotoxicity. Biochem Pharmacol. 1980;29:3003-10.

18. Timour Q, Nony P, Lang J, Lakhal M, Trillet V, Faucon G. Doxorubicin concentrations in plasma and myocardium and their respective roles in cardiotoxicity. Cardiovasc Drugs Ther. 1988;1: 559-60.

19. Carvalho FS, Burgeiro A, Garcia R, Moreno AJ, Carvalho RA, Oliveira PJ. Doxorubicin-Induced Cardiotoxicity: From Bioenergetic Failure and Cell Death to Cardiomyopathy. Med Res Rev. 2014;34:106-35.

20. Štěrba M, Popelová O, Vávrová A, Jirkovský E, Kovaříková P, Geršl V, et al. Oxidative stress, redox signaling, and metal chelation in anthracycline cardiotoxicity and pharmacological cardioprotection. Antioxidants Redox Signal. 2013;18:899-929.

21. Angsutararux P, Luanpitpong S, Issaragrisil S. ChemotherapyInduced Cardiotoxicity: Overview of the Roles of Oxidative Stress. Oxid Med Cell Longev. Hindawi Publishing Corporation; 2015;2015:1-13.

22. Šimůnek T, Štěrba M, Popelová $O$, Adamcová M, Hrdina R, Gerši V. Anthracycline-induced cardiotoxicity: Overview of studies examining the roles of oxidative stress and free cellular iron. Pharmacol Rep. 2009;61:154-71.

23. Lipshultz SE, Franco VI, Sallan SE, Adamson PC, K. Steiner R, Swain SM, et al. Dexrazoxane for reducing anthracycline-related cardiotoxicity in children with cancer: An update of the evidence. Prog Pediatr Cardiol. 2014;36:39-49.

24. Zhang S, Liu X, Bawa-Khalfe T, Lu LS, Lyu YL, Liu LF, et al. Identification of the molecular basis of doxorubicin-induced cardiotoxicity. Nat Med. 2012;18:1639-42.

25. Varga Z V., Ferdinandy P, Liaudet L, Pacher P. Drug-induced mitochondrial dysfunction and cardiotoxicity. Am J Physiol Heart Circ Physiol [Internet]. American Physiological Society; 2015;309:H1453-H1467. Available from: http://ajpheart. physiology.org/lookup/doi/10.1152/ajpheart.00554.2015

26. Xiao B, Hong L, Cai X, Mei S, Zhang P, Shao L. The true colors of autophagy in doxorubicin-induced cardiotoxicity (Review). Oncol Lett. 2019; 18:2165-72.

27. Bartlett JJ, Trivedi PC, Pulinilkunnil T. Autophagic dysregulation in doxorubicin cardiomyopathy. J Mol Cell Cardiol. 2017;104:18 .

28. Koleini N, Kardami E. Autophagy and mitophagy in the context of doxorubicin-induced cardiotoxicity. Oncotarget. 2017;8: 46663-80.

29. Caulfield JB, Wolkowicz PE. Myocardial connective tissue alterations. Toxicol Pathol. 1990;18:488-96.

30. Hardie DG, Carling D, Sim A TR. The AMP-activated protein kinase: a multisubstrate regulator of lipid metabolism. Trends Biochem Sci. 1989;14:20-23.

31. Hardie DG. AMP-activated/SNF1 protein kinases: Conserved guardians of cellular energy. Nat Rev Mol Cell Biol. 2007;8: 774-85.

32. Dyck JRB, Lopaschuk GD. AMPK alterations in cardiac physiology and pathology: Enemy or ally? J Physiol. 2006;574:95-112. 
33. Russell RR, Li J, Coven DL, Pypaert M, Zechner C, Palmeri M, et al. AMP-activated protein kinase mediates ischemic glucose uptake and prevents postischemic cardiac dysfunction, apoptosis, and injury. J Clin Invest. 2004;114:495-503.

34. Zaha VG, Young LH. AMP-activated protein kinase regulation and biological actions in the heart. Circ Res. 2012;111:800-14.

35. Woods A, Johnstone SR, Dickerson K, Leiper FC, Fryer LGD, Neumann D, et al. LKB1 is the upstream kinase in the AMPactivated protein kinase cascade. Curr Biol. 2003;13:2004-8.

36. Hawley SA, Pan DA, Mustard KJ, Ross L, Bain J, Edelman AM, et al. Calmodulin-dependent protein kinase kinase- $\beta$ is an alternative upstream kinase for AMP-activated protein kinase. Cell Metab. 2005;2:9-19.

37. Woods A, Vertommen D, Neumann D, Türk R, Bayliss J, Schlattner $U$, et al. Identification of phosphorylation sites in AMP-activated protein kinase (AMPK) for upstream AMPK kinases and study of their roles by site-directed mutagenesis. J Biol Chem. 2003;278:28434-42.

38. Woods A, Salt I, Scott J, Hardie DG, Carling D. The $\alpha 1$ and $\alpha 2$ isoforms of the AMP-activated protein kinase have similar activities in rat liver but exhibit differences in substrate specificity in vitro. FEBS Lett. 1996;397:347-51.

39. Suzuki A, Okamoto S, Lee S, Saito K, Shiuchi T, Minokoshi Y. Leptin stimulates fatty acid oxidation and peroxisome proliferatoractivated receptor gene expression in mouse $\mathrm{C} 2 \mathrm{C} 12$ myoblasts by changing the subcellular localization of the 2 form of AMP-activated protein kinase. Mol Cell Biol. 2007;27:4317-27.

40. Davies SP, Helps NR, Cohen PTW, Hardie DG. 5'-AMP inhibits dephosphorylation, as well as promoting phosphorylation, of the AMP-activated protein kinase. Studies using bacterially expressed human protein phosphatase- $2 \mathrm{C} \alpha$ and native bovine protein phosphatase-2AC. FEBS Lett. 1995;377:421-5.

41. Gimeno-Alcañiz JV, Sanz P. Glucose and type 2A protein phosphatase regulate the interaction between catalytic and regulatory subunits of AMP-activated protein kinase. J Mol Biol. 2003;333: 201-9.

42. MOORE F, WEEKES J, HARDIE DG. Evidence that AMP triggers phosphorylation as well as direct allosteric activation of rat liver AMP-activated protein kinase: A sensitive mechanism to protect the cell against ATP depletion. Eur J Biochem. 1991;199:691-7.

43. Voss M, Paterson J, Kelsall IR, Martín-Granados C, Hastie CJ, Peggie MW, et al. Ppm1E is an in cellulo AMP-activated protein kinase phosphatase. Cell Signal. 2011;23:114-24.

44. Schaffer BE, Levin RS, Hertz NT, Maures TJ, Schoof ML, Hollstein PE, et al. Identification of AMPK phosphorylation sites reveals a network of proteins involved in cell invasion and facilitates large-scale substrate prediction. Cell Metab. 2015;22:90721.

45. Herzig S, Shaw RJ. AMPK: Guardian of metabolism and mitochondrial homeostasis. Nat Rev Mol Cell Biol. 2018;19:121-35.

46. Luiken JJFP, Coort SLM, Willems J, Coumans WA, Bonen A, Van der Vusse GJ, et al. Contraction-induced fatty acid translocase/ CD36 translocation in rat cardiac myocytes is mediated through AMP-activated protein kinase signaling. Diabetes. 2003;52:162734.

47. Marsin AS, Bertrand L, Rider MH, Deprez J, Beauloye C, Vincent MF, et al. Phosphorylation and activation of heart PFK-2 by AMPK has a role in the stimulation of glycolysis during ischaemia. Curr Biol. 2000;10:1247-55.

48. Zong H, Ren JM, Young LH, Pypaert M, Mu J, Birnbaum MJ, et al. AMP kinase is required for mitochondrial biogenesis in skeletal muscle in response to chronic energy deprivation. Proc Natl Acad Sci U S A. 2002;99:15983-7.
49. Sciarretta S, Forte M, Frati G, Sadoshima J. New insights into the role of mtor signaling in the cardiovascular system. Circ Res. 2018;122:489-505.

50. Winder WW, Hardie DG. AMP-activated protein kinase, a metabolic master switch: Possible roles in Type 2 diabetes. Am J Physiol - Endocrinol Metab. 1999;277:40-1.

51. Lu Q, Li X, Liu J, Sun X, Rousselle T, Ren D, et al. AMPK is associated with the beneficial effects of antidiabetic agents on cardiovascular diseases. Biosci Rep. 2019;39:1-15.

52. Kim TT, Dyck JRB. Is AMPK the savior of the failing heart? Trends Endocrinol Metab. 2015;26:40-8.

53. Li X, Liu J, Lu Q, Ren D, Sun X, Rousselle T, et al. AMPK: A therapeutic target of heart failure - not only metabolism regulation. Biosci Rep. Portland Press Ltd; 2019;39.

54. Li Y, Wang Y, Zou M, Chen C, Chen Y, Xue R, et al. AMPK blunts chronic heart failure by inhibiting autophagy. Biosci Rep. 2018;38.

55. Daskalopoulos EP, Dufeys C, Bertrand L, Beauloye C, Horman S. AMPK in cardiac fibrosis and repair: Actions beyond metabolic regulation. J Mol Cell Cardiol. 2016;91:188-200.

56. Kim J, Kundu M, Viollet B, Guan KL. AMPK and mTOR regulate autophagy through direct phosphorylation of Ulk1. Nat Cell Biol. 2011;13:132-41.

57. Khalil H, Kanisicak O, Prasad V, Correll RN, Fu X, Schips T, et al. Fibroblast-specific TGF- $\beta$-Smad $2 / 3$ signaling underlies cardiac fibrosis. J Clin Invest. 2017;127:3770-83.

58. Lin $\mathrm{H}, \mathrm{Li} \mathrm{N}, \mathrm{He} \mathrm{H}$, Ying $\mathrm{Y}$, Sunkara $\mathrm{S}$, Luo L, et al. AMPK inhibits the stimulatory effects of TGF- $\beta$ on Smad $2 / 3$ activity, cell migration, and epithelial-to-mesenchymal transition. Mol Pharmacol. 2015;88:1062-71.

59. Tokarska-Schlattner M, Zaugg M, Da Silva R, Lucchinetti E, Schaub MC, Wallimann T, et al. Acute toxicity of doxorubicin on isolated perfused heart: Response of kinases regulating energy supply. Am J Physiol - Hear Circ Physiol. 2005;289.

60. Barpe DR, Rosa DD, Froehlich PE. Pharmacokinetic evaluation of doxorubicin plasma levels in normal and overweight patients with breast cancer and simulation of dose adjustment by different indexes of body mass. Eur J Pharm Sci. 2010;41:458-63.

61. Gratia S, Kay L, Potenza L, Seffouh A, Novel-Chate V, Schnebelen C, et al. Inhibition of AMPK signalling by doxorubicin: At the crossroads of the cardiac responses to energetic, oxidative, and genotoxic stress. Cardiovasc Res. 2012;95:290-9.

62. Wu R, Wang HL, Yu HL, Cui XH, Xu MT, Xu X, et al. Doxorubicin toxicity changes myocardial energy metabolism in rats. Chem Biol Interact. 2016;244:149-58.

63. Yang W, Park IJ, Yun H, Im DU, Ock S, Kim J, et al. AMPactivated protein kinase $\alpha 2$ and $\mathrm{E} 2 \mathrm{~F} 1$ transcription factor mediate doxorubicin-induced cytotoxicity by forming a positive signal loop in mouse embryonic fibroblasts and non-carcinoma cells. J Biol Chem. 2014;289:4839-52.

64. Chen MB, Wu XY, Gu JH, Guo QT, Shen WX, Lu PH. Activation of AMP-activated protein kinase contributes to doxorubicin-induced cell death and apoptosis in cultured myocardial H9C2 cells. Cell Biochem Biophys. 2011;60:311-22.

65. Pointon AV, Walker TM, Phillips KM, Luo J, Riley J, Zhang SD, et al. Doxorubicin in vivo rapidly alters expression and translation of myocardial electron transport chain genes, leads to ATP loss and caspase 3 activation. PLoS One. 2010;5:1-17.

66. Li R, Huang Y, Semple I, Kim M, Zhang Z, Lee JH. Cardioprotective roles of sestrin 1 and sestrin 2 against doxorubicin cardiotoxicity. Am J Physiol - Hear Circ Physiol. 2019;317: H39-48

67. Lee JH, Budanov AV, Karin M. Sestrins orchestrate cellular metabolism to attenuate aging. Cell Metab. 2013;18:792-801. 
68. Owen MR, Doran E, Halestrap AP. Evidence that metformin exerts its anti-diabetic effects through inhibition of complex 1 of the mitochondrial respiratory chain. Biochem J. 2000;348:607-14.

69. Sun W, Lee TS, Zhu M, Gu C, Wang Y, Zhu Y, et al. Statins activate AMP-activated protein kinase in vitro and in vivo. Circulation. 2006;114:2655-62.

70. Hawley SA, Gadalla AE, Olsen GS, Grahame HD. The antidiabetic drug metformin activates the AMP-activated protein kinase cascade via an adenine nucleotide-independent mechanism. Diabetes. 2002;51:2420-5.

71. Lan F, Weikel KA, Cacicedo JM, Ido Y. Resveratrol-induced AMP-activated protein kinase activation is cell-type dependent: Lessons from basic research for clinical application. Nutrients. 2017;9.

72. Saha AK, Avilucea PR, Ye JM, Assifi MM, Kraegen EW, Ruderman NB. Pioglitazone treatment activates AMP-activated protein kinase in rat liver and adipose tissue in vivo. Biochem Biophys Res Commun. 2004;314:580-5.

73. Merrill GF, Kurth EJ, Hardie DG, Winder WW. AICA riboside increases AMP-activated protein kinase, fatty acid oxidation, and glucose uptake in rat muscle. Am J Physiol - Endocrinol Metab. 1997;273.

74. Olivier S, Foretz M, Viollet B. Promise and challenges for direct small molecule AMPK activators. Biochem Pharmacol. 2018;153: $147-58$.

75. Coven DL, Hu X, Cong L, Bergeron R, Shulman GI, Hardie DG, et al. Physiological role of AMP-activated protein kinase in the heart: Graded activation during exercise. Am J Physiol Endocrinol Metab. 2003;285.

76. Edwards AG, Donato AJ, Lesniewski LA, Gioscia RA, Seals DR, Moore RL. Life-long caloric restriction elicits pronounced protection of the aged myocardium: A role for AMPK. Mech Ageing Dev. 2010;131:739-42.

77. Kobashigawa LC, Xu YC, Padbury JF, Tseng YT, Yano N. Metformin protects cardiomyocyte from doxorubicin induced cytotoxicity through an AMP activated protein kinase dependent signaling pathway: An in Vitro study. PLoS One. 2014;9.

78. Barreto-Torres G, Hernandez JS, Jang S, Rodríguez-Muñoz AR, Torres-Ramos CA, Basnakian AG, et al. The beneficial effects of amp kinase activation against oxidative stress are associated with prevention of PPAR $\alpha$-cyclophilin D interaction in cardiomyocytes. Am J Physiol Heart Circ Physiol. 2015;308: 749-58.

79. Asensio-López MC, Lax A, Pascual-Figal DA, Valdés M, Sánchez-Más J. Metformin protects against doxorubicin-induced cardiotoxicity: Involvement of the adiponectin cardiac system. Free Radic Biol Med. 2011;51:1861-71.

80. Konishi M, Haraguchi G, Ohigashi H, Ishihara T, Saito K, Nakano $\mathrm{Y}$, et al. Adiponectin protects against doxorubicin-induced cardiomyopathy by antiapoptotic effects through AMPK up-regulation. Cardiovasc Res. 2011;89:309-19.

81. Arafa MH, Mohammad NS, Atteia HH, Abd-Elaziz HR. Protective effect of resveratrol against doxorubicin-induced cardiac toxicity and fibrosis in male experimental rats. J Physiol Biochem. 2014;70:701-11.

82. Cappetta D, Esposito G, Piegari E, Russo R, Ciuffreda LP, Rivellino A, et al. SIRT1 activation attenuates diastolic dysfunction by reducing cardiac fibrosis in a model of anthracycline cardiomyopathy. Int J Cardiol. 2016;205:99-110.

83. Liu MH, Shan J, Li J, Zhang Y, Lin XL. Resveratrol inhibits doxorubicin-induced cardiotoxicity via sirtuin 1 activation in H9C2 cardiomyocytes. Exp Ther Med. 2016;12:1113-8.

84. Liu MH, Lin XL, Guo DM, Zhang Y, Yuan C, Tan TP, et al. Resveratrol protects cardiomyocytes from doxorubicin-induced apoptosis through the AMPK/P53 pathway. Mol Med Rep. 2016;13:1281-6.
85. Gu J, Hu W, Song ZP, Chen YG, Zhang DD, Wang CQ. Resveratrol-induced autophagy promotes survival and attenuates doxorubicin-induced cardiotoxicity. Int Immunopharmacol. 2016;32:1-7.

86. Zakaria N, Khalil SR, Awad A, Khairy GM. Quercetin Reverses Altered Energy Metabolism in the Heart of Rats Receiving Adriamycin Chemotherapy. Cardiovasc Toxicol. 2018;18:10919.

87. Wang S, Song P, Zou MH. Inhibition of AMP-activated protein kinase $\alpha(\mathrm{AMPK} \alpha)$ by doxorubicin accentuates genotoxic stress and cell death in mouse embryonic fibroblasts and cardiomyocytes: Role of p53 and SIRT1. J Biol Chem. 2012;287:8001-12.

88. Chen K, Xu X, Kobayashi S, Timm D, Jepperson T, Liang Q. Caloric restriction mimetic 2-deoxyglucose antagonizes doxorubicin-induced cardiomyocyte death by multiple mechanisms. J Biol Chem. 2011;286:21993-2006.

89. Wang S, Wang Y, Zhang Z, Liu Q, Gu J. Cardioprotective effects of fibroblast growth factor 21 against doxorubicin-induced toxicity via the SIRT1/LKB1/AMPK pathway. Cell Death Dis. 2017;8: e3018.

90. Abbas NAT, Kabil SL. Liraglutide ameliorates cardiotoxicity induced by doxorubicin in rats through the Akt/GSK-3 $\beta$ signaling pathway. Naunyn Schmiedebergs Arch Pharmacol. Springer Verlag; 2017;390:1145-1153.

91. Lee KH, Cho H, Lee S, Woo JS, Cho BH, Kang JH, et al. Enhanced-autophagy by exenatide mitigates doxorubicin-induced cardiotoxicity. Int J Cardiol. 2017;232:40-7.

92. Liu D, Ma Z, Di S, Yang Y, Yang J, Xu L, et al. AMPK/PGC1 $\alpha$ activation by melatonin attenuates acute doxorubicin cardiotoxicity via alleviating mitochondrial oxidative damage and apoptosis. Free Radic Biol Med. 2018;129:59-72.

93. Andreadou I, Mikros E, Ioannidis K, Sigala F, Naka K, Kostidis S, et al. Oleuropein prevents doxorubicin-induced cardiomyopathy interfering with signaling molecules and cardiomyocyte metabolism. J Mol Cell Cardiol. 2014;69:4-16.

94. Johnson R, Shabalala S, Louw J, Kappo AP, Muller CJF. Aspalathin reverts doxorubicin-induced cardiotoxicity through increased autophagy and decreased expression of p53/mTOR/p62 signaling. Molecules. 2017;22.

95. Low Wang CC, Galinkin JL, Hiatt WR. Toxicity of a novel therapeutic agent targeting mitochondrial complex I. Clin Pharmacol Ther. 2015;98:551-9.

96. Pasquel FJ, Klein R, Adigweme A, Hinedi Z, Coralli R, Pimentel JL, et al. Metformin-associated lactic acidosis. Am J Med Sci. 2015;349:263-7.

97. Kuan W, Beavers CJ, Guglin ME. Still sour about lactic acidosis years later: role of metformin in heart failure. Heart Fail Rev. 2018;23:347-53.

98. Dziubak A, Wójcicka G, Wojtak A, Bełtowski J. Metabolic effects of metformin in the failing heart. Int J Mol Sci. 2018;19.

99. Gundewar S, Calvert JW, Jha S, Toedt-Pingel I, Ji SY, Nunez D, et al. Activation of AMP-activated protein kinase by metformin improves left ventricular function and survival in heart failure. Circ Res. 2009; 104:403-11.

100. Wessels B, Ciapaite J, Van Den Broek NMA, Nicolay K, Prompers JJ. Metformin impairs mitochondrial function in skeletal muscle of both lean and diabetic rats in a Dose-dependent manner. PLoS One. 2014;9.

101. Rena G, Hardie DG, Pearson ER. The mechanisms of action of metformin. Diabetologia. 2017;60:1577-85.

102. Boyle JG, Logan PJ, Jones GC, Small M, Sattar N, Connell JMC, et al. AMP-activated protein kinase is activated in adipose tissue of individuals with type 2 diabetes treated with metformin: A randomised glycaemia-controlled crossover study. Diabetologia. 2011;54:1799-809. 
103. Musi N, Hirshman MF, Nygren J, Svanfeldt M, Bavenholm P, Rooyackers O, et al. Metformin increases AMP-activated protein-kinase activity in skeletal muscle of subjects with type 2 diabetes. Diabetes. 2002;51:2074-81.

104. Zhou G, Myers R, Li Y, Chen Y, Shen X, Fenyk-Melody J, et al. Role of AMP-activated protein kinase in mechanism of metformin action. J Clin Invest. 2001;108:1167-74.

105. Wang Y, Yang Z, Zheng G, Yu L, Yin Y, Mu N, et al. Metformin promotes autophagy in ischemia/reperfusion myocardium via cytoplasmic AMPK $\alpha 1$ and nuclear AMPK $\alpha 2$ pathways. Life Sci. 2019;225:64-71.

106. Xiao H, Ma X, Feng W, Fu Y, Lu Z, Xu M, et al. Metformin attenuates cardiac fibrosis by inhibiting the TGF1-Smad3 signalling pathway. Cardiovasc Res. 2010;87:504-13.

107. Zilinyi R, Czompa A, Czegledi A, Gajtko A, Pituk D, Lekli I, et al. The cardioprotective effect of metformin in doxorubicin-induced cardiotoxicity: The role of autophagy. Molecules. 2018;23.

108. Wong AKF, Howie J, Petrie JR, Lang CC. AMP-activated protein kinase pathway: A potential therapeutic target in cardiometabolic disease. Clin Sci. 2009;116:607-20.

109. Hyoung CC, Song P, Xie Z, Wu Y, Xu J, Zhang M, et al. Reactive nitrogen species is required for the activation of the AMP-activated protein kinase by statin in vivo. J Biol Chem. 2008;283:2018697.

110. Kou R, Sartoretto J, Michel T. Regulation of Rac1 by simvastatin in endothelial cells. Differential roles of AMP-activated protein kinase and calmodulin-dependent kinase- $\beta$. J Biol Chem. 2009;284:14734-43.

111. Yoshida M, Shiojima I, Ikeda H, Komuro I. Chronic doxorubicin cardiotoxicity is mediated by oxidative DNA damage-ATM-p53apoptosis pathway and attenuated by pitavastatin through the inhibition of Rac1 activity. J Mol Cell Cardiol. 2009;47:698-705.

112. Huelsenbeck J, Henninger C, Schad A, Lackner KJ, Kaina B, Fritz G. Inhibition of Rac1 signaling by lovastatin protects against anthracycline-induced cardiac toxicity. Cell Death Dis. 2011;2.

113. Henninger C, Huelsenbeck S, Wenzel P, Brand M, Huelsenbeck J, Schad A, et al. Chronic heart damage following doxorubicin treatment is alleviated by lovastatin. Pharmacol Res. 2015;91:1-10.

114. Kim YH, Park SM, Kim M, Kim SH, Lim SY, Ahn JC, et al. Cardioprotective effects of rosuvastatin and carvedilol on delayed cardiotoxicity of doxorubicin in rats. Toxicol Mech Methods. 2012;22:488-95.

115. Zhang H, Lu X, Liu Z, Du K. Rosuvastatin reduces the pro-inflammatory effects of adriamycin on the expression of HMGB1 and RAGE in rats. Int J Mol Med. 2018;42:3415-23.

116. Svvs R, Trivedi PP, Kushwaha S, Vikram A, Jena GB. Protective role of atorvastatin against doxorubicin-induced cardiotoxicity and testicular toxicity in mice. J Physiol Biochem. 2013;69:513-25.

117. Riad A, Bien S, Westermann D, Becher PM, Loya K, Landmesser $\mathrm{U}$, et al. Pretreatment with statin attenuates the cardiotoxicity of doxorubicin in mice. Cancer Res. 2009;69:695-9.

118. Seicean S, Seicean A, Plana JC, Budd GT, Marwick TH. Effect of statin therapy on the risk for incident heart failure in patients with breast cancer receiving anthracycline chemotherapy: An observational clinical cohort study. J Am Coll Cardiol. 2012;60:2384-90.

119. Mattivi F. Solid phase extraction of trans-resveratrol from wines for HPLC analysis. Z Lebensm Unters Forsch. 1993;196:522-5.

120. Block G, Jensen CD, Norkus EP, Dalvi TB, Wong LG, McManus $\mathrm{JF}$, et al. Usage patterns, health, and nutritional status of long-term multiple dietary supplement users: A cross-sectional study. Nutr J. 2007;6.

121. Zordoky BNM, Robertson IM, Dyck JRB. Preclinical and clinical evidence for the role of resveratrol in the treatment of cardiovascular diseases. Biochim Biophys Acta - Mol Basis Dis. 1852;2014:1155-77.
122. Dyck GJB, Raj P, Zieroth S, Dyck JRB, Ezekowitz JA. The effects of resveratrol in patients with cardiovascular disease and heart failure: A narrative review. Int J Mol Sci. 2019;20.

123. Xu D, Li Y, Zhang B, Wang Y, Liu Y, Luo Y, et al. Resveratrol alleviate hypoxic pulmonary hypertension via anti-inflammation and anti-oxidant pathways in rats. Int J Med Sci. 2016;13:942-54.

124. Sung MM, Das SK, Levasseur J, Byrne NJ, Fung D, Kim TT, et al. Resveratrol treatment of mice with pressure-overloadinduced heart failure improves diastolic function and cardiac energy metabolism. Circ Hear Fail. 2015;8:128-37.

125. Gu J, Hu W, Zhang DD. Resveratrol, a polyphenol phytoalexin, protects against doxorubicin-induced cardiotoxicity. J Cell Mol Med. 2015;19:2324-8.

126. Lan F, Cacicedo JM, Ruderman N, Ido Y. SIRT1 modulation of the acetylation status, cytosolic localization, and activity of LKB1: Possible role in AMP-activated protein kinase activation. J Biol Chem. 2008;283:27628-35.

127. Ruan Y, Dong C, Patel J, Duan C, Wang X, Wu X, et al. SIRT1 suppresses doxorubicin-induced cardiotoxicity by regulating the oxidative stress and p38MAPK pathways. Cell Physiol Biochem. 2015;35:1116-24.

128. Xu X, Chen K, Kobayashi S, Timm D, Liang Q. Resveratrol attenuates doxorubicin-induced cardiomyocyte death via inhibition of p70 S6 kinase 1- mediated autophagy. J Pharmacol Exp Ther. 2012;341:183-95.

129. Gu J, Qi FY, Li ZH, An PJ, Ying YJ, Feng ZJ, et al. Resveratrol suppresses doxorubicin-induced cardiotoxicity by disrupting E2F1 mediated autophagy inhibition and apoptosis promotion. Biochem Pharmacol. 2018;150:202-13.

130. Lehmann JM, Moore LB, Smith-Oliver TA, Wilkison WO, Willson TM, Kliewer SA. An antidiabetic thiazolidinedione is a high affinity ligand for peroxisome proliferator-activated receptor $\gamma($ PPAR $\gamma)$. J Biol Chem. 1995;270:12953-6.

131. Fryer LGD, Parbu-Patel A, Carling D. The anti-diabetic drugs rosiglitazone and metformin stimulate AMP-activated protein kinase through distinct signaling pathways. J Biol Chem. 2002;277: 25226-32.

132. Yamauchi T, Kamon J, Minokoshi Y, Ito Y, Waki H, Uchida S, et al. Adiponectin stimulates glucose utilization and fatty-acid oxidation by activating AMP-activated protein kinase. Nat Med. 2002;8:1288-95.

133. Brunmair B, Staniek K, Gras F, Scharf N, Althaym A, Clara R, et al. Thiazolidinediones, like metformin, inhibit respiratory complex I: a common mechanism contributing to their antidiabetic actions? Diabetes. 2004;53:1052-9.

134. Skildum A, Dornfeld K, Wallace K. Mitochondrial amplification selectively increases doxorubicin sensitivity in breast cancer cells with acquired antiestrogen resistance. Breast Cancer Res Treat. 2011;129:785-97.

135. Deus CM, Zehowski C, Nordgren K, Wallace KB, Skildum A, Oliveira PJ. Stimulating basal mitochondrial respiration decreases doxorubicin apoptotic signaling in $\mathrm{H} 9 \mathrm{C} 2$ cardiomyoblasts. Toxicology. 2015;334:1-11.

136. Lago RM, Singh PP, Nesto RW. Congestive heart failure and cardiovascular death in patients with prediabetes and type 2 diabetes given thiazolidinediones: a meta-analysis of randomised clinical trials. Lancet. 2007;370:1129-36.

137. Mullane K. Acadesine: The prototype adenosine regulating agent for reducing myocardial ischaemic injury. Cardiovasc Res. 1993;27:43-7.

138. Sabina RL, Kernstine KH, Boyd RL, Holmes EW, Swain JL. Metabolism of 5-amino-4-imidazolecarboxamide riboside in cardiac and skeletal muscle. Effects on purine nucleotide synthesis. J Biol Chem. 1982;257:10178-83.

139. Corton JM, Gillespie JG, Hawley SA, Hardie DG. 5Aminoimidazole-4-carboxamide ribonucleoside: a specific 
method for activating AMP-activated protein kinase in intact cells? Eur J Biochem. 1995;229:558-65.

140. Kukidome D, Nishikawa T, Sonoda K, Imoto K, Fujisawa K, Yano M, et al. Activation of AMP-activated protein kinase reduces hyperglycemia induced mitochondrial reactive oxygen species production and promotes mitochondrial biogenesis in human umbilical vein endothelial cells. Diabetes. 2006;55:120-7.

141. O'Neill HM, Lally JS, Galic S, Thomas M, Azizi PD, Fullerton $\mathrm{MD}$, et al. AMPK phosphorylation of ACC2 is required for skeletal muscle fatty acid oxidation and insulin sensitivity in mice. Diabetologia. 2014;57:1693-702.

142. Ren J, Xu X, Wang Q, Ren SY, Dong M, Zhang Y. Permissive role of AMPK and autophagy in adiponectin deficiency-accentuated myocardial injury and inflammation in endotoxemia. J Mol Cell Cardiol. 2016;93:18-31.

143. Nam DH, Kim E, Benham A, Park HK, Soibam B, Taffet GE, et al. Transient activation of AMPK preceding left ventricular pressure overload reduces adverse remodeling and preserves left ventricular function. FASEB J. 2019;33:711-21.

144. Boon H, Bosselaar M, Praet SFE, Blaak EE, Saris WHM, Wagenmakers AJM, et al. Intravenous AICAR administration reduces hepatic glucose output and inhibits whole body lipolysis in type 2 diabetic patients. Diabetologia. 2008;51:1893-900.

145. Moussa A, Li J. AMPK in myocardial infarction and diabetes: the yin/yang effect. Acta Pharm Sin B. 2012;2:368-78.

146. Scudiero O, Nigro E, Monaco ML, Oliviero G, Polito R, Borbone $\mathrm{N}$, et al. New synthetic AICAR derivatives with enhanced AMPK and ACC activation. J Enzyme Inhib Med Chem. 2016;31:74853.

147. Guigas B, Sakamoto K, Taleux N, Reyna SM, Musi N, Viollet B, et al. Beyond AICA riboside: In search of new specific AMPactivated protein kinase activators. IUBMB Life. 2009;61:18-26.

148. Kouzi SA, Uddin MN. Aerobic exercise training as a potential cardioprotective strategy to attenuate doxorubicin-induced cardiotoxicity. J Pharm Pharm Sci. 2016;19:399-410.

149. Lee Y, Kwon I, Jang Y, Cosio-Lima L, Barrington P. Endurance exercise attenuates doxorubicin-induced cardiotoxicity. Med Sci Sports Exerc. 2020;52:25-36.

150. Nair N, Gongora E. Heart failure in chemotherapy-related cardiomyopathy: Can exercise make a difference? BBA Clin. 2016;6: 69-75.

151. Kirkham AA, Shave RE, Bland KA, Bovard JM, Eves ND, Gelmon KA, et al. Protective effects of acute exercise prior to doxorubicin on cardiac function of breast cancer patients: A proof-of-concept RCT. Int J Cardiol. 2017;245:263-70.

152. Kirkham AA, Eves ND, Shave RE, Bland KA, Bovard J, Gelmon $\mathrm{KA}$, et al. The effect of an aerobic exercise bout $24 \mathrm{~h}$ prior to each doxorubicin treatment for breast cancer on markers of cardiotoxicity and treatment symptoms: A. Breast Cancer Res Treat. 2018;167:719-29.

153. Cantó C, Auwerx J. Calorie restriction: Is AMPK a key sensor and effector? Physiology. 2011;26:214-24.

154. Mitra MS, Donthamsetty S, White B, Latendresse JR, Mehendale HM. Mechanism of protection of moderately diet restricted rats against doxorubicininduced acute cardiotoxicity. Toxicol Appl Pharmacol. 2007;225:90-101.

155. Hall SE, Smuder AJ, Hayward R. Effects of calorie restriction and voluntary exercise on doxorubicin-induced cardiotoxicity. Integr Cancer Ther. 2019;18.

156. Kawaguchi T, Takemura G, Kanamori H, Tsujimoto A, Goto K, Ogino A, et al. Abstract 10979: Impairment of autophagic flux in doxorubicin cardiotoxicity and its restoration and improvement of cardiac function by prior starvation. Circulation [Internet]. 2012;126:A10979-. Available from: http://circ.ahajournals.org/ cgi/content/meeting_abstract/126/21_MeetingAbstracts/A10979
157. Feng D, Biftu T, Romero FA, Kekec A, Dropinski J, Kassick A, et al. Discovery of MK-8722: A systemic, direct pan-activator of AMP-activated protein kinase. ACS Med Chem Lett. 2018;9: 39-44.

158. Myers RW, Guan HP, Ehrhart J, Petrov A, Prahalada S, Tozzo E, et al. Systemic pan-AMPK activator MK-8722 improves glucose homeostasis but induces cardiac hypertrophy. Science. 2017;357: 507-11.

159. Ge W, Zhang W, Gao R, Li B, Zhu H, Wang J. IMM-H007 improves heart function via reducing cardiac fibrosis. Eur $\mathrm{J}$ Pharmacol. 2019;857.

160. Cool B, Zinker B, Chiou W, Kifle L, Cao N, Perham M, et al. Identification and characterization of a small molecule AMPK activator that treats key components of type 2 diabetes and the metabolic syndrome. Cell Metab. 2006;3:403-16.

161. Sanders MJ, Ali ZS, Hegarty BD, Heath R, Snowden MA, Carling D. Defining the mechanism of activation of AMP-activated protein kinase by the small molecule A-769662, a member of the thienopyridone family. J Biol Chem. 2007;282:32539-48.

162. Kim AS, Miller EJ, Wright TM, Li J, Qi D, Atsina K, et al. A small molecule AMPK activator protects the heart against ischemia-reperfusion injury. J Mol Cell Cardiol. 2011;51:24-32.

163. Timmermans AD, Balteau M, Gélinas R, Renguet E, Ginion A, de Meester C, et al. A-769662 potentiates the effect of other AMPactivated protein kinase activators on cardiac glucose uptake. Am J Physiol Heart Circ Physiol. 2014;306.

164. Soo JSS, Ng CH, Tan SH, Malik RA, Teh YC, Tan BS, et al Metformin synergizes 5-fluorouracil, epirubicin, and cyclophosphamide (FEC) combination therapy through impairing intracellular ATP production and DNA repair in breast cancer stem cells. Apoptosis. 2015;20:1373-87.

165. Zheng B, Peng Y, Wu W, Ma J, Zhang Y, Guo Y, et al. Synthesis and structure-activity relationships of pyrazolo-[3,4-b]pyridine derivatives as adenosine 5'-monophosphate-activated protein kinase activators. Arch Pharm (Weinheim). 2019;352.

166. Zinman B, Wanner C, Lachin JM, Fitchett D, Bluhmki E, Hantel $\mathrm{S}$, et al. Empagliflozin, cardiovascular outcomes, and mortality in type 2 diabetes. N Engl J Med. 2015;373:2117-28.

167. Fitchett D, Zinman B, Wanner C, Lachin JM, Hantel S, Salsali A, et al. Heart failure outcomes with empagliflozin in patients with type 2 diabetes at high cardiovascular risk: Results of the EMPAREG OUTCOME® trial. Eur Heart J. 2016;37:1526-34.

168. Ye Y, Jia X, Bajaj M, Birnbaum Y. Dapagliflozin Attenuates Na+/ $\mathrm{H}+$ Exchanger-1 in Cardiofibroblasts via AMPK Activation. Cardiovasc Drugs Ther. 2018;32:553-8.

169. Hawley SA, Ford RJ, Smith BK, Gowans GJ, Mancini SJ, Pitt $\mathrm{RD}$, et al. The Na+/glucose cotransporter inhibitor canagliflozin activates AMPK by inhibiting mitochondrial function and increasing cellular AMP levels. Diabetes. 2016;65:2784-94.

170. Oh CM, Cho S, Jang JY, Kim H, Chun S, Choi M, et al. Cardioprotective potential of an SGLT2 inhibitor against doxorubicin-induced heart failure. Korean Circ J. 2019;49:1183-95.

171. Yang CC, Chen YT, Wallace CG, Chen KH, Cheng BC, Sung PH, et al. Early administration of empagliflozin preserved heart function in cardiorenal syndrome in rat. Biomed Pharmacother. 2019; 109:658-70.

172. Wang X, Wang XL, Chen HL, Wu D, Chen JX, Wang XX, et al. Ghrelin inhibits doxorubicin cardiotoxicity by inhibiting excessive autophagy through AMPK and p38-MAPK. Biochem Pharmacol. 2014;88:334-50.

173. Cao Y, Shen T, Huang X, Lin Y, Chen B, Pang J, et al. Astragalus polysaccharide restores autophagic flux and improves cardiomyocyte function in doxorubicin-induced cardiotoxicity. Oncotarget. 2017;8:4837-48. 
174. Wu R, Yao PA, Wang HL, Gao Y, Yu HL, Wang L, et al. Effect of fermented cordyceps sinensis on doxorubicin-induced cardiotoxicity in rats. Mol Med Rep. 2018;18:3229-41.

175. Chen C, Jiang L, Zhang M, Pan X, Peng C, Huang W, et al. Isodunnianol alleviates doxorubicin-induced myocardial injury by activating protective autophagy. Food Funct. 2019;10:2651-7.

176. Tang F, Zhou X, Wang L, Shan L, Li C, Zhou H, et al. A novel compound DT-010 protects against doxorubicin-induced cardiotoxicity in zebrafish and $\mathrm{H} 9 \mathrm{c} 2$ cells by inhibiting reactive oxygen species-mediated apoptotic and autophagic pathways. Eur J Pharmacol. 2018;820:86-96.

177. Hawley SA, Fullerton MD, Ross FA, Schertzer JD, Chevtzoff C, Walker KJ, et al. The ancient drug salicylate directly activates AMP-activated protein kinase. Science. 2012;336:918-22.

178. Cheng T, Liu D, Griffin JH, Fernández JA, Castellino F, Rosen $\mathrm{ED}$, et al. Activated protein C blocks p53-mediated apoptosis in ischemic human brain endothelium and is neuroprotective. Nat Med. 2003;9:338-42.

179. Miller EJ, Li J, Leng L, McDonald C, Atsumi T, Bucala R, et al. Macrophage migration inhibitory factor stimulates AMP-activated protein kinase in the ischaemic heart. Nature. 2008;451:578-82.

180. Giordano SH, Lin YL, Kuo YF, Hortobagyi GN, Goodwin JS. Decline in the use of anthracyclines for breast cancer. J Clin Oncol. 2012;30:2232-9.

181. Feleszko W, Młynarczuk I, Bałkowiec-Iskra EZ, Czajka A, Świtaj $\mathrm{T}$, Stokłosa T, et al. Lovastatin potentiates antitumor activity and attenuates cardiotoxicity of doxorubicin in three tumor models in mice. Clin Cancer Res. 2000;6:2044-52.
182. Salminen A, Kauppinen A, Kaarniranta K. AMPK activation inhibits the functions of myeloid-derived suppressor cells (MDSC): impact on cancer and aging. J Mol Med. 2019;97:1049-64.

183. Tyszka-Czochara M, Konieczny P, Majka M. Recent advances in the role of AMP-activated protein kinase in metabolic reprogramming of metastatic cancer cells: targeting cellular bioenergetics and biosynthetic pathways for anti-tumor treatment. J Physiol Pharmacol. 2018;69.

184. Marinello PC, Panis C, Silva TNX, Binato R, Abdelhay E, Rodrigues JA, et al. Metformin prevention of doxorubicin resistance in MCF-7 and MDAMB- 231 involves oxidative stress generation and modulation of cell adaptation genes. Sci Rep. 2019;9.

185. El-Masry OS, Brown BL, Dobson PRM. Effects of activation of AMPK on human breast cancer cell lines with different genetic backgrounds. Oncol Lett. 2012;3:224-8.

186. Van Den Neste E, Cazin B, Janssens A, González-Barca E, Terol MJ, Levy V, et al. Acadesine for patients with relapsed/refractory chronic lymphocytic leukemia (CLL): A multicenter phase I/II study. Cancer Chemother Pharmacol. 2013;71:581-91.

187. Saif MW, Rajagopal S, Caplain J, Grimm E, Serebrennikova O, Das M, et al. A phase I delayed-start, randomized and pharmacodynamic study of metformin and chemotherapy in patients with solid tumors. Cancer Chemother Pharmacol. 2019;84:1323-31.

Publisher's Note Springer Nature remains neutral with regard to jurisdictional claims in published maps and institutional affiliations. 